by the involvement of the sartorius muscle, which is not paralyzed in poliomyelitic paralysis, and of the sensory fibres of the anterior crural nerve, and by the normal condition of the tibialis anticus. Still later the ulnar nerve of the right hand was affected. The course of the disease justified the diagnosis of progressive polyneuritis, probably idiopathic in origin. Lead was not thought to be the cause of the trouble, because the paralysis progressed after the man had stopped working with type, and because saturnine paralysis, when in rare cases it appears in the lower extremities, never attacks the thigh muscles alone. Lead paralysis also is very uncommon in type-setters. The case is peculiar in its course and want of symmetry, and the name of mononeuritis multiplex may well be applied to it. As the ulnar was the only nerve affected for three months, the impropriety of entirely separating localized neuritis (mononeuritis) from the multiple form is well demonstrated.

Spiller.

A Case of So-called Paramyoclonus with Pitenomena of CompULston. (Berliner klinische Wochenschrift, No, 44, I8g6.) By L. Stembo, M.D.

Stembo reports a case in which all the cardinal symptoms of myoclonia, as given by Friedreich and Unverricht, were present. Coprolalia as seen in the maladie des tics convulsifs, was also observed. There was no echolalia. The writer can only refer to one similar case. This was reported by Spitzlka.

Dr. Stembo regards his case as a proof of the impossibility of making a sharp distinction between the various forms of convulsive movements. These occur in many different nervous diseases, and especially in hysteria. Myoclonia in most cases is of a hysterical nature, even though no other stigmata may be present. Monosymptomatic hysteria is by no means uncommon. Some of these convulsive movements may be due to organic disease, but in no case are they more than symptomatic. The writer warns us against the too strict separation of the different forms of spasmodic movements.

SPILILER.

\title{
Hemiplegia and EPilepsy.
}

M. Férè ( $L a$ Méd. Moderne, May 5 th, 1897 ) briefly reported to the Société de Biologie a case of hemiplegia and epilepsy. His observations were upon a case of epilepsy in which there had been. a cerebral hemorrhage, resulting in left hemiplegia. In the attacks of epilepsy which followed it was remarked that the hemiplegic side remained unaffected by the convusions which continued to manifest themselves as before upon the right side. - Mitchell.

\section{PSYCHOLOGY.}

Experiments on Memory Types. Psychological Review, May, I897.

Chatuncey J. Hawkins (Yale) tested auditory and visual senses in public school and college students. For the auditory tests he read aloud three groups of three numbers each at the rate of one number per'second. The first group was read once, the second was read twice, and the third group three times. He found that the second reading nearly always weakened the memory a trifle, that the subjects could not recite the reading quite so well as they did after the first reading. The third reading produced a very marked improvement. $\mathrm{He}$ also observed that the younger pupils nearly always reproduced the numbers without hesitation, while the college students always hesitated and required more time to reproduce the list. 
In his visual tests two lists of words were placed upon the blackboard and covered. The first test was then exposed for thirty seconds, and the second list was exposed at the rate of one word every two seconds (thirteen short familiar words in a list). This test was tried on pupils ranging from eight to fifteen years of age, and revealed the fact that successive visual memory is much better in the younger pupils than simultaneous visual memory, there being a difference of 22 per cent. at the age of eight, while there was a difference of only I per cent. at the age of fifteen. In students from fifteen to twenty years of age it was found that simultaneous exposure gave a much better meniory than successive exposure.

Auditory memory was found to be much better than visual memory in pupils from eight to twelve years of age, a fact probably due to their being accustomed to a large amount of auditory work. A like reason, probably, accounts for the fact that students ranging from fifteen to twenty years of age showcd a much better visual than auditory menory.

Christison.

"Reaction Types." Psychological Review, May, 1897.

Farrand (Columbia) tested the two noted pianists, Rosenthal and Sieveking, as to their reaction time to sound. The Hipp chronoscope was used, and they were to raise the two for efingers of the right hand when the signal was given by a tap with a metal hammer. Neither. subject knew that the other was to be tested. Rosenthal made seven records as follows (times in 0 ): $110,118,119,112,119,123,123$, giving an average reaction time of 117.7 , and an average variation of 3.8 . Sievelking's reaction time was II4, 114, I17, 120, 108, an average of II6.6, and an average variation of 2 . No instruction as to attention was given either subject, but Rosenthal declared his entire attention was on the signal, while Sieveking was as positive his attention was on his reacting hand. Rosenthal repeated the experiment, this time giving his attention to his reacting fingers instead of the signal. The result was, $250,230,270,268$, an average of 254.5 , and an average variation of 14.5. Sieveking was asked to react with his attention on the signal instead of on his hand as before. He attempted to do so, but declared it impossible and declined to proceed. The musical training and characteristics of these two artists are said to be diametrically opposed.

Cattell (Columbia) thinks these experiments support the idea "that people react most quickly and regularly in the" way in which they were used to reacting, and that when the reflex character of the reaction is disturbed, the times become longer and more irregular."

Baldwin (Princeton) remarks, in opposition to Wundt: "The existence of "types' of simple reaction can no longer be ignored by allyone."

ChRISTISON.

Is Trional a Useful Hypnotic, and does it Possess any AdvantAges over Sulfonal? By Prof. J. Von Mering, Halle (New Eng. Med. Monthly, Jan., r897).

It has been observed that in certain individuals sulfonal has a cumulative action leading to a severe disturbance of the general health (hæmatoporphyrinuria), which in some cases lead to a fatal issue. In many cases in which the dosage had been carefully regulated the action was continued beyond the desired period. Experiments showed that trional has all the useful properties of sulfonal in a higher degree, while the undesirable effects are absent or less marked. Morro found that trional was more easily and completely decomposed within the organism, and that the ultinate products were more easily eliminated. Since the introduction of trional six cases of toxic phenomena have been observed. In two or three of these hrematoporphyrin was found in 